\title{
Fatores de Risco para Macrossomia Fetal em Gestações Complicadas por Diabete e Hiperglicemia Diária
}

\section{Risk Factors for Fetal Macrosomy in Pregnancies Complicated by Diabetes and Daily Hyperglycemia}

Autora: Luciane Teresa Rodrigues Lima Kerche

Orientadora: Profa. Dra. Iracema de Mattos Paranhos Calderon

Dissertação de Mestrado apresentada à Disciplina de Obstetrícia do Departamento de Ginecologia e Obstetrícia a Faculdade de Medicina de Botucatu - UNESP, em 24 de maio de 2004.

Objetivo: identificar fatores de risco para a macrossomia fetal na população de gestantes portadoras de diabete ou hiperglicemia diária, tratadas com dieta/insulina. Método: estudo retrospectivo, tipo caso-controle, incluindo 803 pares de mães e recém-nascidos desta população específica, distribuídos em dois grupos macrossômicos (casos, $\mathrm{n}=241$ ) e não-macrossômicos (controles, $n=561$ ). Foram comparadas variáveis relativas à idade, paridade, peso e índice de massa corporal (IMC) pré-gravídico, ganho de peso (GP), antecedentes de diabete, hipertensão arterial e tabagismo, tipo e classificação do diabete e indicadores do controle glicêmico no terceiro trimestre. As médias foram avaliadas pelo teste $\mathrm{F}$ e as variáveis categorizadas foram submetidas à análise univariada, utilizando-se o teste do qui-quadrado $\left(\chi^{2}\right)$. Os resultados significativos foram incluídos no modelo de regressão múltipla, para identificação do risco independente de macrossomia, considerando-se OR, IC 95\% e valor de $p$. Para todos as análises foi estabelecido o limite de significância estatística de 5\% ( $p<0,05)$.

Resultados: observou-se na análise univariada, asso- ciação significativa entre macrossomia e GP $>16 \mathrm{~kg}$, IMC e $\geq 25 \mathrm{~kg} / \mathrm{m}^{2}$, antecedentes pessoais, obstétricos e, especificamente, o de macrossomia, o diagnóstico de diabete gestacional (grupos IIA + IIB de Rudge), e as médias glicêmicas inadequadas no terceiro trimestre, a total $(\mathrm{MG}) \geq 120 \mathrm{mg} / \mathrm{dL}$ e média de glicemia pósprandial (MPP) $\geq 130 \mathrm{mg} / \mathrm{dL}$. Na análise de regressão múltipla, o GP >16 kg (OR = 1,79; IC 95\% = 1,23-1,60), o IMC e $\geq 25 \mathrm{~kg} / \mathrm{m}^{2}$ (OR = 1,83; IC 95\% = 1,27-2,64), o antecedente pessoal de diabete $(\mathrm{OR}=1,56$; IC $95 \%=$ $1,05-2,31$ ) e de macrossomia (OR $=2,37$; IC 95\% $=1,60$ $3,50)$ e a $\mathrm{MG} \geq 120 \mathrm{mg} / \mathrm{dL}$ no terceiro trimestre $(\mathrm{OR}=$ 1,78 ; IC $95 \%=1,13-2,80$ ) confirmaram risco independente para macrossomia nestas gestações de risco. Conclusão: o GP $>16 \mathrm{~kg}$, o IMC $\geq 25 \mathrm{~kg} / \mathrm{m}^{2}$, a MG $\geq 120 \mathrm{mg} /$ $\mathrm{dL}$ no terceiro trimestre e a presença de antecedentes pessoal de diabete ou de macrossomia foram identificados como fatores de risco para macrossomia fetal em gestantes portadoras de diabete ou de hiperglicemia diária.

Palavras-chave: Diabete.Complicações da gravidez. Macrossomia fetal.

\section{Indução do Parto a Termo com Feto Vivo com Misoprostol Vaginal: Ensaio Clínico Aberto}

Induction of Delivery at Term with a Live Fetus with Vaginal Misoprostol: An Open Clinical Assay

Aluna - Zuleika Studart Sampaio

Orientador - Prof. Dr. Carlos Augusto Alencar Júnior

Tese apresentada ao programa de Pós-Graduação em Tocoginecologia do Departamento de Saúde Materno-Infantil da Universidade Federal do Ceará, em 12 de dezembro de 2003.

Objetivo: analisar a efetividade do misoprostol para indução do parto e determinar os principais fatores associados ao parto transpelvino.

Sujeitos e Métodos: ensaio clínico aberto, não randomizado, incluindo 61 gestantes internadas ba Maternidade-Escola Assis Chateaubriand, em Fortaleza (CE). Todas tinham gestação única, feto vivo, idade gestacional $\geq 37$ semanas e escore de Bishop $\leq 7$. Utilizou-se a dose de 50mcg de misoprostol via vaginal, repetindo-se a cada seis horas, ate o máximo de quadro doses. Realizou-se análise uni e multivariada para determinação da associação entre parto vaginal e variáveis preditoras e construiu-se curvas ROC para escores de Bishop e escore Bishop e paridade.

Resultados: O intervalo entre administração da primeira dose e o parto variou entre 3 e 37 horas (média em torno de 12,7 horas). Aproximadamente 79\% das pacientes apresentaram desencadeamento trabalho de parto após única dose. Verificou-se taquissistolia em $23 \%$ dos casos, com 6,6\% de síndrome de hiperestimula- ção. A freqüência de parto vaginal foi de 55,7\%. As medianas dos escores de apgar, para o primeiro e o quinto minutos, foram de oito e nove. Não ocorreram óbitos fetais ou neonatais. Encontrou-se associação significativa do parto vaginal com a paridade (um ou mais partos anteriores) e escore de Bishop $\geq 4$, enquanto a taquissistolia reduziu a chance de parto vaginal. Através de curva ROC para os escores de Bishop e a paridade como determinantes do parto vaginal, encontrou-se VPP de 100\%, com sensibilidade de 63,2\%. A área sob a curva foi de $86,8 \%(\mathrm{p}=0,023)$.

Conclusões: O misoprostol vaginal, na dose de $50 \mathrm{mcg}$, a cada seis horas, foi efetivo para indução do parto, resultando em $55,7 \%$ de partos vaginais, com resultados perinatais favoráveis. Os fatores preditivos mais importantes para parto vaginal foram a paridade (um ou mais partos) e escore de Bishop $\geq 4$.

Palavras-chave: Misoprostol. Trabalho de parto induzido. Trabalho de parto. Prostaglandinas. 